\title{
An Evolutionarily Stable Strategy Model for the Evolution of Dimorphic Development in the Butterfly Maculinea rebeli, a Social Parasite of Myrmica Ant Colonies
}

\author{
Thomas Hovestadt, ${ }^{1, *}$ Oliver Mitesser, ${ }^{1, \uparrow}$ Graham W. Elmes, ${ }^{2, \ddagger}$ Jeremy A. Thomas, ${ }^{2, \S}$ and Michael E. Hochberg ${ }^{3, \|}$
}

1. Field Station Fabrikschleichach, University of Würzburg, Glashüttenstraße 5, 96181 Rauhenebrach, Germany;

2. Centre for Ecology and Hydrology, Winfrith Technology Centre, Dorchester, Dorset DT2 8ZD, United Kingdom;

3. Department of Genetics and Environment, University of Montepellier, Place Eugene Bataillon, CC 065, 34095 Montpellier Cedex 5, France

Submitted May 22, 2006; Accepted November 21, 2006;

Electronically published January 31, 2007

Online enhancement: appendix.

ABSTRACt: Caterpillars of the butterfly Maculinea rebeli develop as parasites inside ant colonies. In intensively studied French populations, about $25 \%$ of caterpillars mature within 1 year (fast-developing larvae [FDL]) and the others after 2 years (slow-developing larvae [SDL]); all available evidence indicates that this ratio is under the control of egg-laying females. We present an analytical model to predict the evolutionarily stable fraction of FDL $\left(p_{\mathrm{ESS}}\right)$. The model accounts for added winter mortality of SDL, general and kin competition among caterpillars, a competitive advantage of SDL over newly entering FDL (priority effect), and the avoidance of renewed infection of ant nests by butterflies in the coming season (segregation). We come to the following conclusions: (1) all factors listed above can promote the evolution of delayed development; (2) kin competition and segregation stabilize $p_{\text {ESS }}$ near 0.5 ; and (3) a priority effect is the only mechanism potentially selecting for $p_{\text {Ess }}<0.5$. However, given the empirical data, $p_{\mathrm{ESS}}$ is predicted to fall closer to 0.5 than to the 0.25 that has been observed. In this particular system,

\footnotetext{
* E-mail: hovestadt@biozentrum.uni-wuerzburg.de.

† E-mail: mitesser@biozentrum.uni-wuerzburg.de.

¥ E-mail: gwe@ceh.ac.uk.

`E-mail: jat@ceh.ac.uk.

" E-mail: hochberg@isem.univ-montp2.fr.
}

Am. Nat. 2007. Vol. 169, pp. 466-480. (c) 2007 by The University of Chicago. 0003-0147/2007/16904-41848\$15.00. All rights reserved. bet hedging cannot explain why more than $50 \%$ of larvae postpone growth. Presumably, other fitness benefits for SDL, for example, higher fertility or longevity, also contribute to the evolution of delayed development. The model presented here may be of general applicability for systems where maturing individuals compete in small subgroups.

Keywords: delayed development, growth dimorphism, evolutionarily stable strategy (ESS), ant-butterfly interaction, social parasitism.

The social parasite of ants Maculinea rebeli Hir. (Lycanidae; Elmes et al. 1991a; Thomas et al. 1998a) and its congeners (Schönrogge et al. 2000; Als et al. 2002; Witek et al. 2006) are remarkable and rare examples of the presence of a distinct larval growth dimorphism with annual and biennial development. The time taken to develop into a mature individual is a critical life-history component of an individual's fitness, with delayed development being almost universally associated with added costs, such as an increased mortality risk during the prolonged developmental period or an increase in generation time. Nonetheless, polymorphism in developmental time has been described for a number of other insect species (Danks 2002). A straightforward explanation is that some individuals are constrained by the lack of critical resources to complete development within a certain time span (e.g., Peck and Walton 2005). However, arguments have been advanced to explain developmental polymorphism on the basis of adaptive strategies, for example, the avoidance of kin competition (Ellner 1986; Kobayashi and Yamamura 2000) and the spread of risk in fluctuating environments ("bet hedging"; Cohen 1966; Ellner 1985; Venable and Brown 1993; van Dooren and Metz 1998; Hopper 1999; Menu et al. 2000; Soula and Menu 2003).

In the case of M. rebeli, the most studied of the cuckoo Maculinea, all caterpillars feed briefly on the flower buds of an initial food plant, Gentiana cruciata (L.), but further development depends on their adoption into a specific host 
ant's nest. Small final-instar caterpillars fall from their gentians on the evening of the final moult and await discovery by foraging Myrmica ant workers (Elmes et al. 1991b), whose larvae they mimic through chemical secretions (Akino et al. 1999) and stridulations (DeVries et al. 1993). Any Myrmica species will retrieve any M. rebeli larva that it finds and carry it to the brood chambers of its nest. Caterpillars do not search for ant colonies, and any individual not collected within 1-3 days invariably dies (Elmes et al. 1991b; G. W. Elmes, unpublished data). The caterpillars then experience a period of integration with the host colony, with initial survival much higher in the nests of Myrmica schencki (Emery), whose secretions it specifically mimics (Akino et al. 1999). Within a week, the secretion of additional mimetic chemicals ensures that the $M$. rebeli caterpillars are nurtured in priority over the ant's brood by the nurse ants, which feed them regurgitations, trophic eggs, and prey (hence the name "cuckoo Maculinea"; Thomas et al. 1998a; Schönrogge et al. 2004). In many $M$. schencki nests, more $M$. rebeli caterpillars are adopted than can be supported by the workers, resulting in strong density-dependent mortality as the caterpillars compete for worker attention (contest competition; Thomas et al. 1993).

After adoption, some $M$. rebeli larvae grow rapidly, overwinter as half-grown caterpillars, complete growth in the following spring, and eclose in early summer to complete their life cycle; we call these larvae the "fast-developing larvae" (FDL). Others grow little in the first summer and overwinter as small caterpillars but grow considerably during the early part of the second summer; they survive a second winter inside the ant colonies and complete their growth in spring - nearly 2 years after entering the ant colony (Elmes et al. 1991a; see fig. 3 in Thomas et al. $1998 a$ for growth trajectories). These larvae we call "slowdeveloping larvae" (SDL). A more complete description of life history is presented in various publications by Thomas, Elmes, and colleagues (Elmes et al. 1991a, 1991b, 1996; Thomas et al. 1991, 1993, 1998b, 2005; Hochberg et al. 1992, 1994; Thomas and Wardlaw 1992; De Vries et al. 1993; Akino et al. 1999).

Laboratory rearing experiments strongly indicate that the "decision" to develop as FDL or SDL is neither constrained by limited resources nor due to manipulation by the ants. (1) The fraction of FDL is not affected by rearing conditions in the ant colony, such as the amount of food available or competition with other caterpillars (Elmes et al. 1991a), as has been reported in other dimorphisms (Edgerly and Livdahl 1992). Nor is it changed if caterpillars are raised singly, although both types of larvae grow relatively larger under such optimal conditions. (2) The fraction of FDL does not vary when the caterpillars are reared by a nonhost species (poorer rearing conditions; Thomas et al. 1998a). (3) The initial weight of a larva when adopted (affected by early growth on the food plant) does not determine subsequent growth strategy in the ant nest-a heavy larva is as likely to grow slowly as a light one (Thomas et al. 1998a, based on unpublished results of detailed laboratory rearing experiments). (4) In the ants, development and worker behavior are predominately determined by the presence of a queen (Hölldobler and Wilson 1990). However, we have never found any evidence for either a positive or negative "queen effect" on caterpillar growth or survival in the cuckoo species of $M$. rebeli or Maculinea alcon (Thomas et al. 2005). Further, there is no evidence that Myrmica larvae ever spend two winters in the nest. (5) We set up pairs of caterpillars and reared them with a fairly low number of workers. If development were in some way manipulated by the worker ants, we would expect more fast/slow pairs, compared to slow/slow or fast/fast pairs, than we would get by a simple binomial distribution based on the overall fraction of fast developers (0.26) recorded by Thomas et al. (1998a). In fact, the results almost exactly fitted the expected binomial distribution, suggesting that development is not altered by the ants but predetermined before the caterpillar enters the ant nest (G. W. Elmes, unpublished data). (6) We established that individual female $M$. rebeli lay a mixture of fast- and slow-developing eggs. Our sample size is small (nine females, each mated once), but we have no evidence that any female produces only fast- or only slow-developing offspring (G. W. Elmes, unpublished data).

These observations strongly indicate that the fraction of caterpillars following the fast or slow growth trajectory is in some way controlled by the mother during oviposition (Elmes et al. 1991a; Thomas et al. 1998a). The proportion of caterpillars taking either trajectory appears to be stable across two isolated but locally widespread populations of M. rebeli from the Spanish Pyrenees and the French Alps. Overall, $0.74( \pm 0.02 \mathrm{SE})$ of all larvae followed the slow development path.

Schönrogge et al. (2000) concluded that a dimorphic development might be a general consequence of parasitizing ant nests, and they presented data for a Microdon hoverfly and other Maculinea species (see also Als et al. 2002; Witek et al. 2006). In particular, they showed that growth dimorphism was present in three distinct geographic races of $M$. alcon. These data suggest that in $M$. alcon, the ratio of fast to slow developers might be nearer $1: 1$; however, neither this nor other studies were replicated on the very large scale that gave the $3: 1$ estimate for $M$. rebeli.

Because of the peculiar life history of M. rebeli, standard explanations (Hopper 1999) for the evolution of diapause cannot easily be applied, because multiple factors are likely to be involved. First, the number of caterpillars entering 


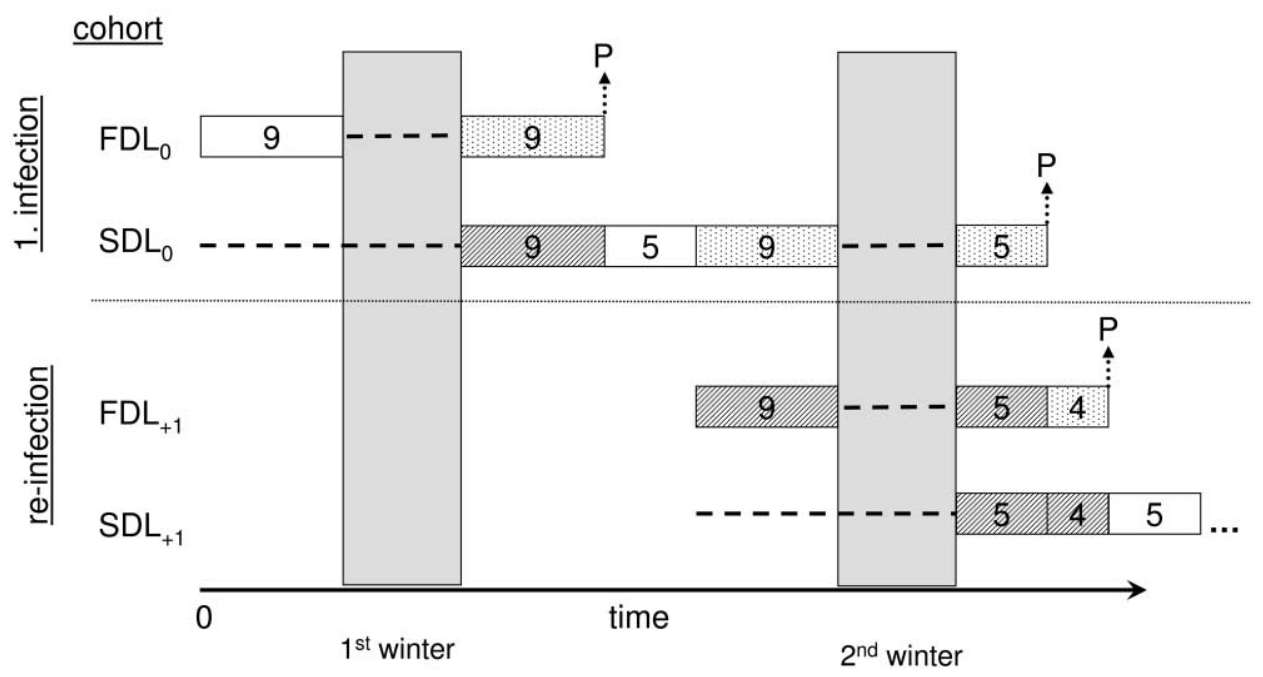

Figure 1: Schematic diagram of life cycle of Maculinea rebeli within host ant colonies (after Thomas et al. 1998a). In case 1, caterpillars enter a previously uninfected colony (first infection) and experience the situation outlined in the upper part of the graph $\left(F D L_{0}\right.$ and $\left.S D L_{0}\right)$; if they enter an infected colony (reinfection), the situation is as depicted in the bottom part of the graph. Fast-developing larvae (FDL; SDL $=$ slow-developing larvae) start to grow immediately for $\sim 9$ weeks; $\mathrm{SDL}_{0}$ delay growth until the next spring. Short dotted arrows labeled " $P$ " indicate time of pupation, and dashed lines indicate periods of dormancy or slow growth. The horizontal bars indicate different phases in development, with the numbers indicating (average) duration in weeks. Bars are hatched if the cohort suffers from competition by larger larvae, dotted if cohort competes with smaller larvae, and not filled if cohort does not compete with larvae from any other cohort. Segregation (see text) prevents reinfection of colonies and thus competition between $\mathrm{FDL}_{+1}$ and $\mathrm{SDL}_{0}$.

an ant colony is typically much larger than the number of caterpillars that can successfully be raised (Hochberg et al. 1992, 1994; Thomas et al. 1998b). If colonies are infected by caterpillars at a constant rate, competition would not be reduced by delayed development. However, some of the arguments introduced in the next paragraphs will be relevant only if (substantial) competition among caterpillars occurs. The intensity of overall competition may thus be a fundamental aspect in the evolution of delayed development.

Second, there is evidence that the caterpillars adopted into a nest are frequently siblings (Elmes et al. 1996; J. A. Thomas, unpublished data). This is a consequence of that fact that only a small proportion of all gentian buds are in a suitable developmental stage for oviposition during the 1-3 days that a typical female butterfly lays eggs (Thomas and Elmes 2001), combined with a shortage of gentians on many, often small, sites (Elmes et al. 1996). Consequently, the eggs of any particular female tend to be clustered. Larvae from eggs laid on the same day on the same clump of gentians generally become available for adoption at the same time and are mostly adopted into the same nest (Elmes et al. 1991b). It is difficult to estimate directly what fraction of larvae entering an ant colony are a single female's offspring, but field data on the oviposition behavior of females (Elmes et al. 1996; G. W. Elmes, un- published data) suggest that it may fall into a range of 0.05-0.25, with higher values occurring on sites with low food plant densities. Because competition among and within cohorts of caterpillars is usually intense, it appears reasonable that avoidance of kin competition is an important factor driving the evolution of the dimorphic growth strategy (Ellner 1986; Kobayashi and Yamamura 2000).

Third, if nests are infected over several years, SDL grow under a different competitive regime than FDL: the latter must compete with both the same year's FDL and last year's SDL for all but the last few weeks of development (slow developers tend to pupate slightly earlier than competing fast developers). The SDL avoid competition by growing little until the previous year's slow developers and their contemporary fast developers near pupation. Consequently, they tend to be larger than any of the new caterpillars taken into the nest (fig. 1).

Elmes and colleagues (1991b) show that large (halfgrown) caterpillars are five times more likely to get attention (grooming and feeding) from worker ants than are small larvae ( $<1 / 4$ grown). After living 1 year in an ant nest, the SDL are larger and presumably so closely integrated with their host's society that the newly adopted FDL are neglected after retrieval by foragers and deposition in the ant brood chamber, especially in nests where the ratio 
Table 1: List of symbols used in text and equations

\begin{tabular}{|c|c|c|}
\hline Symbol & Definition & Comment (parameter range) \\
\hline$p$ & Fraction of caterpillars developing in first year & Evolving strategy parameter $(0-1)$ \\
\hline$L$ & Number of caterpillars competing in ant colony & $L=\varepsilon \times K$ \\
\hline K & Carrying capacity of ant colonies & No effect on evolution of ESS $(0-\infty)$ \\
\hline$\mu$ & Winter survival in second winter & Only for SDL $(0-1)$ \\
\hline$\varepsilon, \varepsilon^{\prime}$ & Intensity of overall competition between caterpillars & $(0-\infty)$ \\
\hline$f, f^{\prime}$ & Fraction of caterpillars entering colony which are offspring of focal female & $(0-1)$ \\
\hline$\alpha$ & Competitive advantage of SDL over newly arriving FDL (see text) & $\begin{array}{l}(0-1) ; 0=\text { symmetric competition; } \\
1=\text { complete dominance of SDL }\end{array}$ \\
\hline E & $\begin{array}{l}\text { Segregation index, i.e., fraction of infected colonies moving away from } \\
\text { host plant neighborhood (see text) }\end{array}$ & $\begin{array}{l}(0-1) ; 0=\text { no segregation; } \\
1=\text { complete segregation }\end{array}$ \\
\hline$c$ & $\begin{array}{l}\text { Added fitness benefits for SDL after emergence, e.g., higher survival, } \\
\text { fecundity }\end{array}$ & $\begin{array}{l}\text { Multiplier for SDL fitness calculated } \\
\text { from model }(1-\infty)\end{array}$ \\
\hline$A$ & Number of adults emerging & $\begin{array}{l}\text { Number of caterpillars surviving until } \\
\text { pupation }\end{array}$ \\
\hline$g$ & Fraction of emerging adults that are offspring of focal female & \\
\hline$O$ & Number of offspring for focal female & $O=A \times g$ \\
\hline
\end{tabular}

Note: ESS = evolutionarily stable strategy; SDL = slow-developing larvae; FDL = fast-developing larvae. Throughout the text, a subscript "R" at any symbol indicates values for the resident strategy, and the subscript " $M$ " indicates values for the mutant (invading) strategy. The subscript " 1 " relates to values derived in the first year (FDL) and the subscript " 2 " to values derived for the second year (SDL). Finally, the subscript " $\mathrm{F}$ " is used if a value relates only to FDL and the suffix "S" if it relates only to SDL. Prime $\left(\varepsilon^{\prime}, f^{\prime}\right)$ indicates values adjusted for feedback effect of resident strategy on competition.

of SDL or ant brood to nurse ants is high (e.g., Elmes et al. 2004; Schönrogge et al. 2004). There is thus evidence that resident SDL have a competitive advantage over newly arriving fast developers that need to grow quickly, especially when larval numbers exceed the carrying capacity of the ant colony (see Thomas et al. 1998a; J. A. Thomas, unpublished data); we term this the "priority effect." Priority effects have been documented in some cross-species examinations (Shorrocks and Bingley 1994; Blaustein and Margalit 1996) and also within species, for example, salamanders (Eitam et al. 2005).

Fourth, ant nests can, in theory, be infected by new $M$. rebeli larvae year after year. However, plant turnover and, especially, the tendency of infested ant colonies to move to new locations (taking along the Maculinea caterpillars already in the nest) remove a fraction of ant colonies into refuges where they are not at risk of a new infection in the coming year (Hochberg et al. 1994; Thomas et al. 1997, 1998b; Thomas and Elmes 1998). Such "ergonomic segregation" leads to a separation of this year's SDL from next year's FDL and reduces competition between the two cohorts of caterpillars (fig. 1); segregation occurs quite frequently (Thomas et al. 1998a).

The above arguments are nonexclusive, making it difficult to assess their quantitative contribution to and interaction in the evolution of delayed development of $M$. rebeli larvae. A thorough evaluation can thus be based only on a formal and quantitative model considering the effects of all of these factors. Here, we present an evolutionarily stable strategy (ESS) model incorporating all of the above parameters. We demonstrate that the evolution of delayed development is in fact adaptive for a wide range of conditions but that only the priority effect can explain why more than $50 \%$ of the caterpillars postpone development into the second year. However, empirical parameter estimates and model predictions are not in exact agreement, and we consider additional factors that potentially contribute to the evolution of delayed development.

\section{Model and Results}

Using the above considerations, we develop a general analytical model to predict the evolutionarily stable fraction of caterpillars developing in the first year ( $p_{\mathrm{ESS}}$; see table 1 for a summary of symbols used throughout the text). We currently have an accurate knowledge of the fraction of caterpillars delaying development $(\sim 0.75)$ but not of the values of all the parameters likely to affect the ESS. Thus, a future test of our model requires estimating these unknown parameters and comparing them with model predictions.

\section{Model Outline}

In the model, we estimate the expected number of offspring to emerge from a single ant nest for a focal female following a given strategy ( $p$ ). According to Ellner (1986), there is a fundamental conflict between mother and offspring over the optimal fraction of delaying descendants. In plants, the fraction of seeds delaying germination is usually under maternal control (Ellner 1986). We make a similar assumption because it is consistent with the em- 
pirical evidence described in the introduction to this article. We thus assume that for each individual larva, the decision to develop within 1 or 2 years follows a "coinflipping" strategy (cf. Menu and Debouzie 1993; Bulmer 1994), with probabilities for either strategy determined by the mother's genotype. In contrast to Ellner's (1986) model, caterpillars can delay development for at most one season (see also Kobayashi and Yamamura 2000). In our model, we account for (1) the role of added densityindependent winter survival $(1-\mu)$ of the SDL delaying development into the second year; (2) the effect of overall competition between caterpillars $(\varepsilon)$; (3) the effect of relatedness between them, that is, the fraction of all caterpillars that are offspring of the focal female $(f)$; (4) the consequence of an existing competitive advantage, that is, priority effect $(\alpha)$ of second-year caterpillars over those newly entering an ant colony; and (5) the influence of a fraction $(E)$ of infected ant colonies moving away from gentian plants and thus avoiding reinfection in the next season (competitive segregation).

We assume that the number of adult butterflies $(A)$ emerging from an ant colony can be scaled to the colony's capacity as

$$
A=\frac{K L}{K+L},
$$

with

$$
L=\varepsilon K,
$$

where $L$ is the number of caterpillars competing in an ant colony and $K$ is the capacity of an ant nest to successfully raise caterpillars. This equation is convenient and at least principally catches the observed asymptotic relationship between the number of Maculinea rebeli caterpillars entering a nest and the number of butterflies successfully emerging from it (Hochberg et al. 1992, 1994). The average capacity $K$ clearly affects overall production of butterflies on any particular site but has, as we see below, no effect on the evolution of the ESS. We thus scale, without loss of generality, all results to a value of $K=1$.

It is further convenient to scale the number of caterpillars entering an ant nest to the colony's carrying capacity (eq. [2]). The parameter $\varepsilon$ thus defines the general level of competition between caterpillars inside the ant colonies, and site-specific differences in $K$ and $\varepsilon$ can be expressed as differences in $\varepsilon$ when $K$ is fixed to unity. Field data collected for $M$. rebeli typically give $K \approx 8$ and $\varepsilon \approx 3.2$ (estimates based on information in Hochberg et al. 1992, 1994; Thomas and Elmes 1998). However, these field data also indicate a systematic difference between sites where $\varepsilon \approx 2.2$, which have low densities of gentian food plants (about $100 /$ ha), and those where $\varepsilon \approx 6$, which have high plant densities (about 2,000 plants/ha). This is due, on the one hand, to small differences in the clumping parameters for gentian distribution and the distribution of eggs on gentians, and it results in higher values of $L$ on highdensity sites. On the other hand, the average carrying capacity $(K)$ of nests is greater on low-density sites (see Elmes et al. 1996) because more host nests live in enemy-free space (Thomas et al. 1998b).

Without loss of generality, we now focus on the reproductive output of a specific female adopting either the resident $\left(p_{\mathrm{R}}\right)$ or a mutant strategy $\left(p_{\mathrm{M}}\right)$. We assume that a fraction $f$ of all the caterpillars entering an ant colony is descended from this focal female (see introduction to this article).

\section{Invasion of a Pure FDL Population}

As a reference, we assume that the population originally consists of fast-developing caterpillars (FDL) only and that nests do not segregate $(E=0)$. It is straightforward to calculate the expected number of offspring emerging from this ant colony and for the specified (as any other) female in such a population of pure FDL (hereafter, the term $O_{\mathrm{R}}$ indicates the expected fitness of the resident strategy):

$$
O_{\mathrm{R}}=f \frac{K L}{K+L}=f \frac{\varepsilon K^{2}}{K(1+\varepsilon)}=f \varepsilon K \frac{1}{1+\varepsilon} .
$$

By definition, an ESS strategy can resist invasion by any other strategy (Maynard Smith and Price 1973; Bulmer 1994; Geritz et al. 1998). To find it, we first address the question of under which conditions a mutant female allocating a fraction $p_{\mathrm{M}}<1$ of its offspring to FDL and consequently $1-p_{\mathrm{M}}$ larvae to slow-developing larvae (SDL) could successfully invade a resident population of pure FDL $\left(p_{\mathrm{R}}=1\right)$. Because we assume a population at equilibrium, lifetime reproductive success $\left(R_{0}\right)$ is an appropriate fitness measure and a criterion for mutant invasibility (Mylius and Diekmann 1995; Heino et al. 1997; van Dooren and Metz 1998; Benton and Grant 1999; Brommer et al. 2004). Consequently, a resident strategy can resist invasion if the expected number of offspring for a mutant female $\left(O_{\mathrm{M}}\right)$ is smaller than that of females following the resident strategy. If otherwise, the mutant strategy invades.

Obviously, a mutant female can expect some offspring to emerge from both years; that is,

$$
O_{\mathrm{M}}=O_{\mathrm{M}, 1}+O_{\mathrm{M}, 2} \text {. }
$$

In "Fitness Components for a Mutant with $p_{\mathrm{M}}<1$ Invading a Resident Population with $p_{\mathrm{R}}=1$ " in the appendix 
a

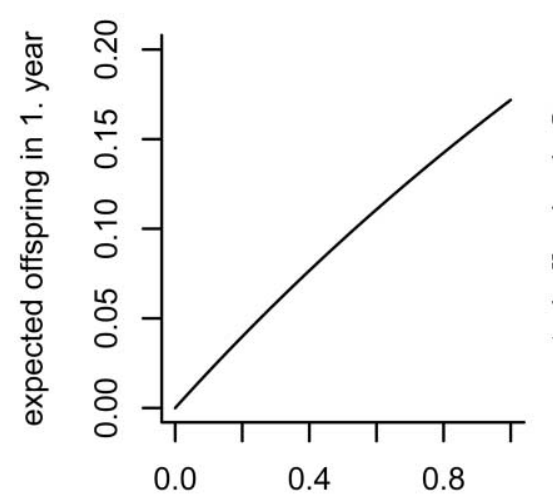

b

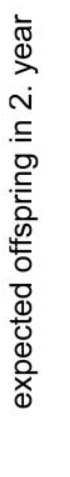

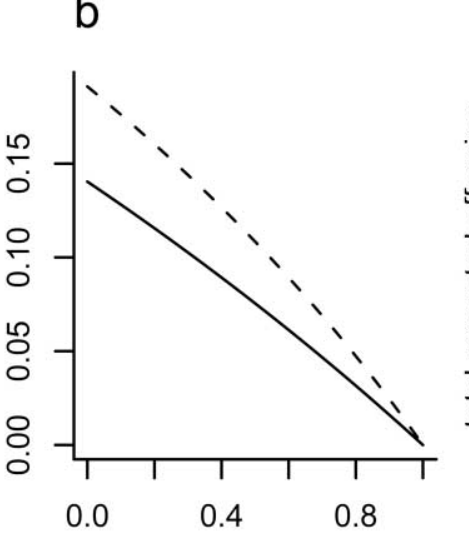

C

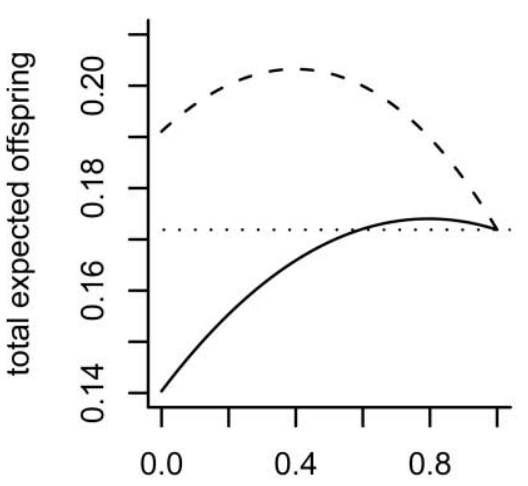

fraction of larvae developing in 1 . year

Figure 2: Relationship between the fraction of caterpillars developing in the first year $\left(p_{\mathrm{M}}\right)$ and the expected number of offspring for a mutant female invading a population of fast developers $\left(p_{\mathrm{R}}=1.0\right)$ with parameters $K=1, \varepsilon=2.2, f=0.25, E=0$, and $\mu=0.95$ (realistic parameters estimated for sites with low host plant density). Plot $a$ shows the number expected in first year, $b$ that in the second year, and $c$ the total number over both years. The solid lines in $b$ and $c$ show the number expected under the assumption of competitive symmetry between fast-developing larvae (FDL) and slow-developing larvae (SDL; $\alpha=0)$; the dashed lines show the number expected under the assumption of a moderate competitive advantage $(\alpha=0.25)$ for SDL over FDL (see text). The dotted line indicates expected offspring number for the resident FDL strategy. Any mutant with an expected fitness above this threshold line can invade a population of pure FDL.

in the online edition of the American Naturalist, we derive the equations that allow the magnitude of the two fitness components $O_{\mathrm{M}, 1}$ and $O_{\mathrm{M}, 2}$ to be estimated. Combining equations (3) and (A11) (eqq. [A1]-[A36] are in the online edition of the American Naturalist), the condition for invasion is $O_{\mathrm{R}}<O_{\mathrm{M}}$; that is,

$$
\begin{aligned}
f_{\varepsilon} K \frac{1}{1+\varepsilon}<f_{\varepsilon} K & \left\{\frac{p_{\mathrm{M}}}{1+\varepsilon\left(1-f+f p_{\mathrm{M}}\right)}\right. \\
& \left.+\frac{a_{\mathrm{M}, 2}\left(1-p_{\mathrm{M}}\right) \mu}{1+\varepsilon\left[1+f\left(1-p_{\mathrm{M}}\right) \mu\right]}\right\}
\end{aligned}
$$

Note that the right side of this equation collapses to the left side if we set $p_{\mathrm{M}}=1$, the resident strategy. The parameter $\mu$ accounts for the added mortality risk the SDL experience in the second winter. At least under laboratory conditions, winter survival is very high in $M$. rebeli (Thomas et al. 1998a), that is, $\mu$ is typically between 0.9 and 0.95 , but it may be lower (e.g., 0.8) under natural conditions. In addition, from the second autumn onward, newly adopted FDL will compete with the SDL from the previous season, requiring us to account for the priority effect, that is, the competitive dominance of SDL over the new cohort of FDL. This is achieved by introducing the model parameter $\alpha$ contained in the term $a_{\mathrm{M}, 2}$ (see eqq.
[A8], [A9] for its derivation); $\alpha$ is constrained to the interval $0 \leq \alpha \leq 1$. A value of $\alpha=0$ implies that resources (ant attendance) are distributed in direct numerical proportion between the FDL and SDL cohorts, that is, that competition between FDL and SDL is symmetrical. A value of $\alpha=1$ implies that the SDL collect all the ant attendance they need for their development before any surplus capacity of ant attendance is directed toward FDL, that is, that SDL completely dominate FDL in competition. In figure 2, we show how the overall fitness $O_{\mathrm{M}}$ compares to $O_{\mathrm{R}}$. The figure illustrates that under competitive symmetry, a mutant with $p_{\mathrm{M}}$ in the range $0.7-1.0$ could invade a population of pure FDL and that even a fairly weak priority effect $(\alpha)$ greatly increases the range of mutants $p_{\mathrm{M}}$ capable of invading a pure FDL population.

\section{Finding the ESS (No Segregation)}

We now turn to the problem of finding the ESS, that is, a resident strategy $p_{\mathrm{R}}$ that cannot be invaded by any other mutant strategy. First, we need to relax the assumption that the resident strategy is $p_{\mathrm{R}}=1$; instead, $p_{\mathrm{R}}$ can take any value between 0 and 1 . From the point of view of any female ovipositing in year 0 and following the resident strategy $p_{R}$, there are now four different types of adults emerging over a 2-year period: adults from FDL and SDL in the first year ( $A_{1, \mathrm{~F}}$ and $A_{1, \mathrm{~S}}$, respectively) and the second 
year $\left(A_{2, \mathrm{~F}}\right.$ and $A_{2, \mathrm{~s}}$, respectively). The expected fitness for a female $\left(O_{R}\right.$, the total number of emerging offspring) thus depends on the number of these emerging adults and her relatedness $(g)$ to them. Clearly, the female is related to neither the $A_{1, \mathrm{~S}}$ nor the $A_{2, \mathrm{~F}}$; that is, $g_{1, \mathrm{~S}}=g_{2, \mathrm{~F}}=0$. The female's expected fitness can thus be calculated by summation of the following terms:

$$
O_{\mathrm{R}}=O_{\mathrm{R}, 1}+O_{\mathrm{R}, 2}=A_{1, \mathrm{~F}} g_{1, \mathrm{~F}}+A_{2, \mathrm{~S}} g_{2, \mathrm{~S}},
$$

where $g_{1, \mathrm{~F}}$ and $g_{2, \mathrm{~s}}$ measure her relatedness to adults emerging from the FDL and SDL in years 1 and 2, respectively.

In "Expected Offspring for a Female Following the Resident Strategy $p_{\mathrm{R}}$ " and "The Effect of Segregation" in the online edition of the American Naturalist, we derive the equation that gives the expected number of offspring for a female following the resident strategy $p_{\mathrm{R}}$ including also the effect of segregation ( $E$; see the introduction to this article). In addition, we must adjust the parameters $\varepsilon$ and $f$ to $\varepsilon^{\prime}$ and $f^{\prime}$ to account for the "feedback" effect the resident strategy itself has on the values of these environmental parameters (Mylius and Diekmann 1995; Metz et al. 1996; see "Adjustment of $\varepsilon$ and $f$ for Resident Strategies $p_{\mathrm{R}}<1$ " in the online edition of the American Naturalist for details). They remain unchanged only for the reference strategy $p_{R}=1$. In the special case of no segregation $(E=0)$, summation of equations (A17) and (A18) yields

$$
\begin{aligned}
O_{\mathrm{R}} & =O_{\mathrm{R}, 1}+O_{\mathrm{R}, 2} \\
& =f^{\prime} \varepsilon^{\prime} K \frac{p_{\mathrm{R}}-\left(a_{\mathrm{R}, 1}-1\right)\left(1-p_{\mathrm{R}}\right) \mu+a_{\mathrm{R}, 2}\left(1-p_{\mathrm{R}}\right) \mu}{1+\varepsilon^{\prime}\left[p_{\mathrm{R}}+\left(1-p_{\mathrm{R}}\right) \mu\right]} .
\end{aligned}
$$

When the resident population is not a pure FDL population, we must also consider competition between FDL and SDL from the previous year in the first season, and we need an additional term $a_{\mathrm{R}, 1}$ to account for this effect, as well as $a_{\mathrm{R}, 2}$, which accounts for the priority effect of SDL over new FDL entering in the next season. Their derivation is based on the same rationale introduced in equations (A8) and (A9) for the calculation of $a_{\mathrm{M}, 2}$ but employs different quantities (eq. [A15]). However, for the case of a homogeneous population, $a_{\mathrm{R}, 1}=a_{\mathrm{R}, 2}$ (set $p_{\mathrm{M}}=p_{\mathrm{R}}$ in eq. [A9] and compare with eq. [A15]). We can thus multiply through equation (7) and recognize that (assuming $E=0$ ) it collapses to

$$
O_{\mathrm{R}}=f^{\prime} \varepsilon^{\prime} K \frac{p_{\mathrm{R}}+\left(1-p_{\mathrm{R}}\right) \mu}{1+\varepsilon^{\prime}\left[p_{\mathrm{R}}+\left(1-p_{\mathrm{R}}\right) \mu\right]} ;
$$

that is, in a homogeneous population the expected number of offspring is not affected by the existence of a priority effect. It is possible to show (eqq. [A33]-[A36]) that in a homogeneous population, the optimal strategy in the absence of segregation $(E=0)$ is always $p_{\mathrm{R}}=1$ and may thus be different from the ESS. If segregation occurs, an analytical solution for the optimal strategy can still be found but cannot be simplified to a useful expression.

The resident strategy $p_{\mathrm{R}}$ will prevail in the population if its expected number of offspring is larger than that of any mutant strategy $p_{\mathrm{M}}$. To estimate the expected fitness of a mutant female whose offspring enter a colony to compete with resident strategy caterpillars, we again must distinguish the four different adult types. However, in a nest with a mutant female, different equations apply ("The Expected Number of Offspring for a Mutant Female with Strategy $p_{\mathrm{M}}$ " in the online edition of the American Naturalist). The simplified equation (A30) for the case of no segregation $(E=0)$ is

$$
\begin{aligned}
O_{\mathrm{M}}= & A_{\mathrm{M}, 1, \mathrm{~F}} g_{\mathrm{M}, 1, \mathrm{~F}}+A_{\mathrm{M}, 2, \mathrm{~s}} g_{\mathrm{M}, 2, \mathrm{~S}} \\
= & \varepsilon^{\prime} K f^{\prime} \frac{\left(1-f^{\prime}\right) p_{\mathrm{R}}+f^{\prime} p_{\mathrm{M}}-\left(a_{\mathrm{M}, 1}-1\right)\left(1-p_{\mathrm{R}}\right) \mu}{1+\varepsilon^{\prime}\left[\left(1-f^{\prime}\right) p_{\mathrm{R}}+f^{\prime} p_{\mathrm{M}}+\left(1-p_{\mathrm{R}}\right) \mu\right]} \\
& \times \frac{p_{\mathrm{M}}}{\left(1-f^{\prime}\right) p_{\mathrm{R}}+f^{\prime} p_{\mathrm{M}}}+a_{\mathrm{M}, 2} \varepsilon^{\prime} K f^{\prime} \\
& \times \frac{\left(1-p_{\mathrm{M}}\right) \mu}{1+\varepsilon^{\prime}\left[p_{\mathrm{R}}+\left(1-f^{\prime}\right)\left(1-p_{\mathrm{R}}\right) \mu+f^{\prime}\left(1-p_{\mathrm{M}}\right) \mu\right]} .
\end{aligned}
$$

To clearly separate the estimates for this situation from the standard situation with resident strategies only, we introduce the terms $a_{\mathrm{M}, i}, A_{\mathrm{M}, i, j}$, and $g_{\mathrm{M}, i, j}$; see the note to table 1 for definitions of subscripts.

A strategy fulfilling the ESS stability criterion (Geritz et al. 1998) meets the following condition (Bulmer 1994), defined for the special case $E=0$ by equations (8) and (9):

$$
O_{\mathrm{R}}>O_{\mathrm{M}} \text { for all } p_{\mathrm{M}} \neq p_{\mathrm{R}} \text {. }
$$

Unfortunately, it was not possible to find a general analytical solution to this equation (but see below), and we thus had to rely on numerical approaches to find the ESS (all done with Mathematica, ver. 4.0; Wolfram Research 1999). Equation (9) gives an implicit and highly nonlinear relationship between $p_{\mathrm{R}}$ and $p_{\mathrm{M}}$. Consequently, we need to scan the complete $p_{\mathrm{R}}-p_{\mathrm{M}}$ parameter space to find those resident strategies $p_{\mathrm{R}}$ that satisfy the ESS condition. Figure 3 gives an example of the effect of differing levels of competitive dominance $\alpha$, larval relatedness $f$, and overall competition $\varepsilon$ on the ESS. Intermediate strategies $\left(0<p_{\text {ESS }}<\right.$ 1) can exist over quite a wide range of values of $\alpha$ as long 
as $f$ is high (as in sites with low gentian density) but only for a small range of $\alpha$ when $f$ is low (as in high-gentiandensity sites). With this procedure, we test for both local ESS stability and "convergence stability" sensu Geritz et al. (1998); in fact, all ESS strategies $0<p_{\text {ESS }}<1$ that we find are also continuously stable strategies.

Equation (9) collapses into equation (8) if both strategy values are equal $\left(p_{\mathrm{R}}=p_{\mathrm{M}}\right)$. Therefore, an ESS resident strategy $0 \leq p_{\text {ESS }} \leq 1$ can exist only if the null at $p_{\mathrm{R}}=p_{\mathrm{M}}$ is of even order. This fact serves to simplify numerical straightforward searching, since it provides a suitable initial point and an exclusion criterion to reject a given resident strategy without checking the whole possible strategy range.

For the special case of $\alpha=0$ and $E=0$, that is, the absence of a priority effect and segregation, an explicit solution for the ESS does in fact exist; however, the equation is fairly complicated and of little practical use. Evaluation of this equation reveals that the ESS approaches values $p_{\mathrm{ESS}}=0.5$ as winter survival $\mu$ approaches values of 1 but that it never falls below this level, whatever the values for $\varepsilon$ or $f$.

For the more general case of $\alpha>0$, we can plot the

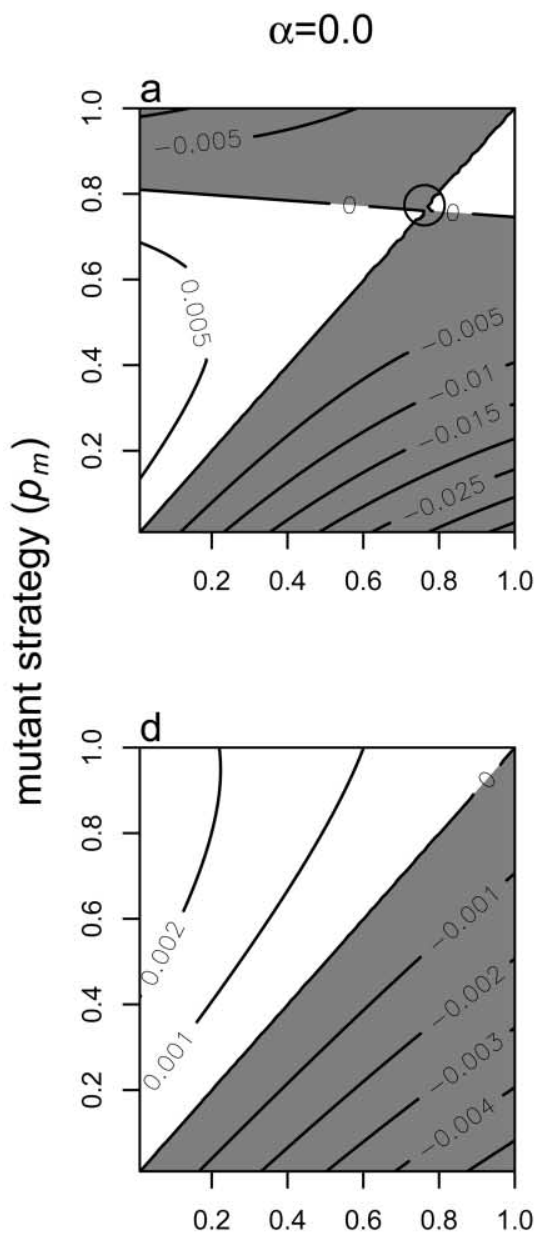

\section{competitive dominance of SDL}

$\alpha=0.05$
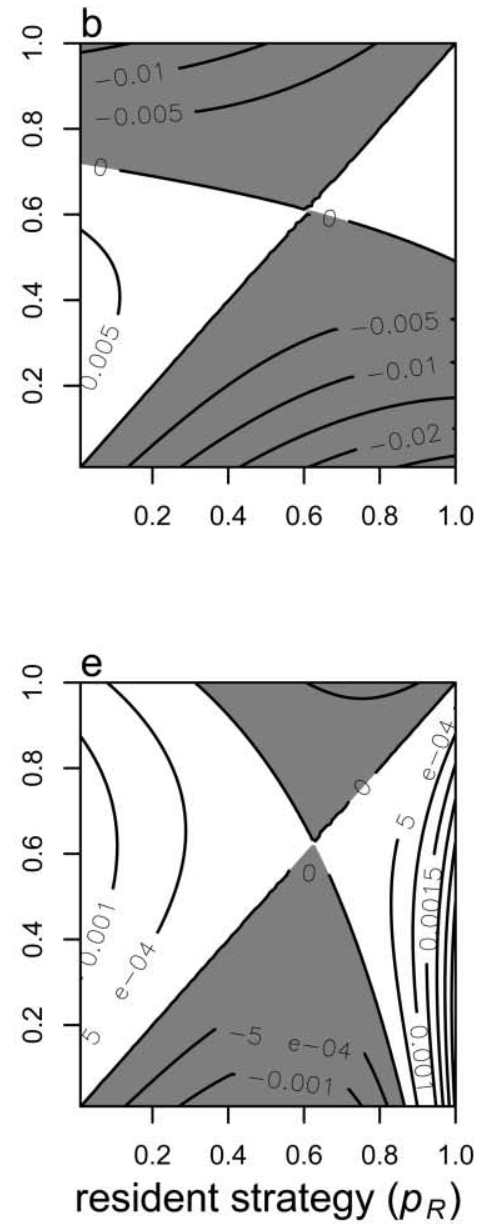

$\alpha=0.1$
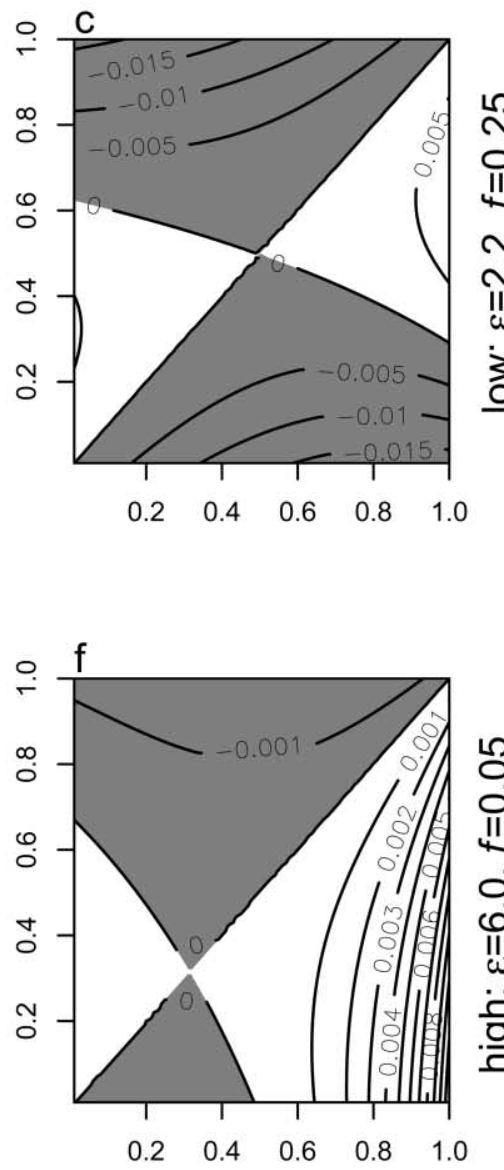

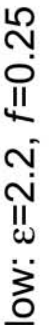

Figure 3: Difference between expected fitness of resident and mutant strategies for $K=1$ and $\mu=0.95$. In $a-c$, we set $f=0.25$ and $\varepsilon=2.2$, values characteristic for sites with low host plant density; in $d-f$, we set $f=0.05$ and $\varepsilon=6$, values more typical for high-density sites. Values for competitive dominance of slow-developing larvae over fast-developing larvae increase from $\alpha=0(a, d)$ to $\alpha=0.05(b, e)$ and $\alpha=0.1(c, f)$. Gray areas indicate regions where the resident strategy is superior to the mutant strategy; in white areas, the reverse is true. An evolutionarily stable strategy (ESS) is thus indicated by a point with gray above and below the main diagonal. In $a$, the ESS is marked by the circle. If the whole upper triangle appears in white (as in $d$ ), then the ESS is $p_{\mathrm{ESS}}=1$; if the whole lower triangle is white, then $p_{\mathrm{ESS}}=0$. According to the criteria outlined by Geritz et al. (1998), ESSs not equal to 0 or 1 are in fact both ESS and convergence stable and can also invade other close strategies; that is, the strategies are continuously stable strategies. 
numerically derived ESS in a two-dimensional plane defined by $\alpha$ and $f$ (fig. 4). The rationale for presenting results in this way is that (1) the empirical estimates for these two parameters are less reliable than those for $\mu, \varepsilon$, and $K$; (2) they have the strongest effect on the ESS; and (3) they show an interesting interaction in their effect on the ESS. Figure 4 shows that $p_{\mathrm{ESS}}$ is highly sensitive to the presence of a priority effect $(\alpha)$, especially on sites where gentian density is high; in other words, when winter survival $\mu$ is high and the fraction $f$ of caterpillars derived from a single female is low, a small change in $\alpha$ would dramatically change the ESS.

However, this sensitivity declines as $f$ becomes larger, and the ESS (potentially) covers a wider range as winter mortality declines. Evidently, the ESS shifts closer to 0.5 if the fraction $f$ of caterpillars expected to derive from a

\section{winter survival SDL}

high: $\mu=0.95$
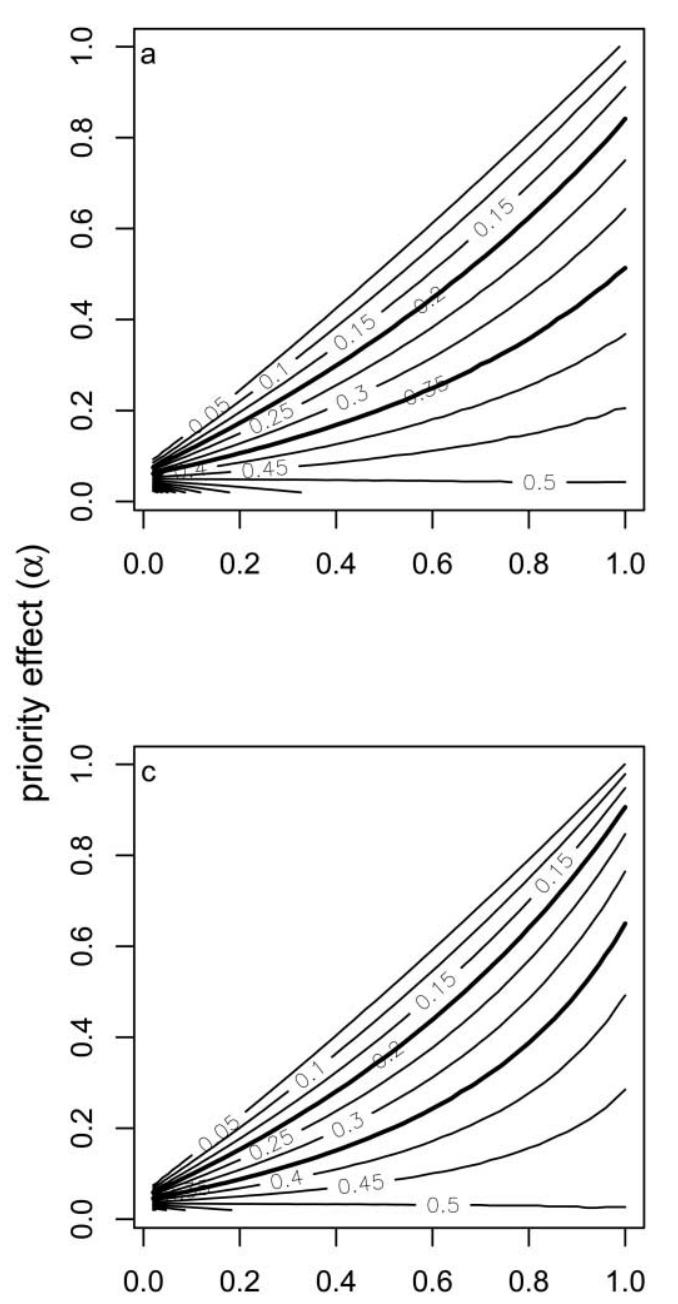

low: $\mu=0.8$
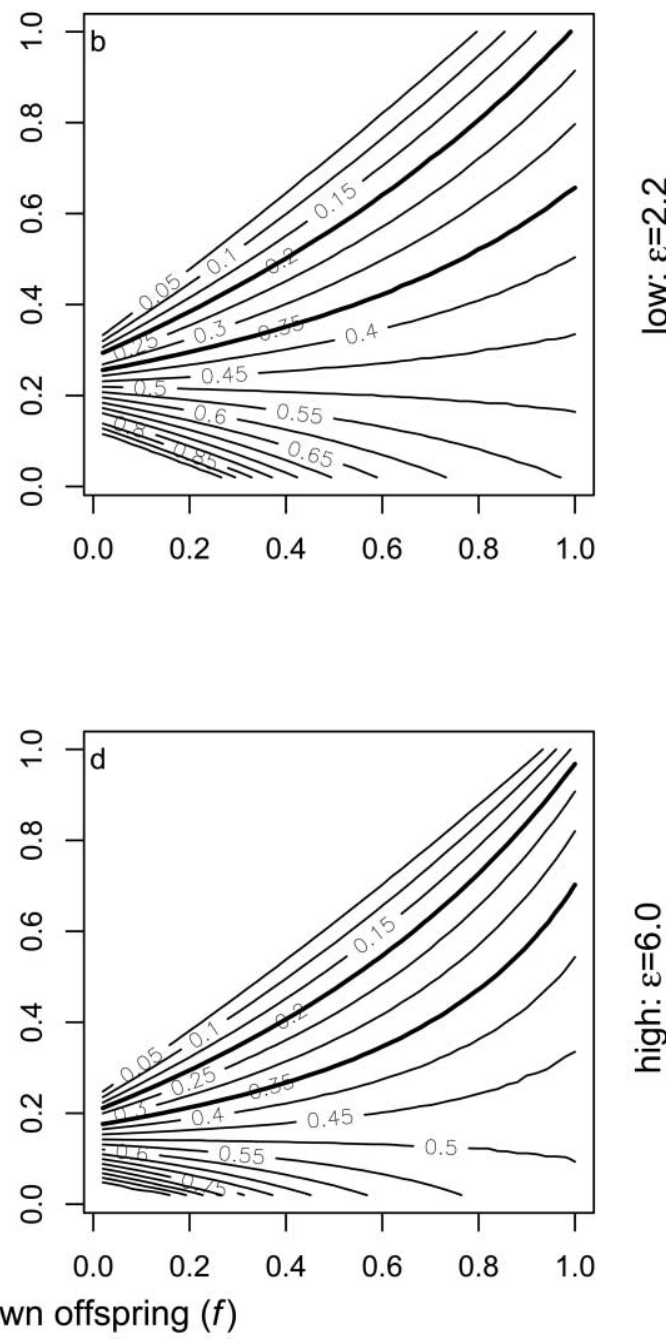

ำ

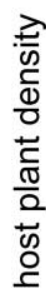

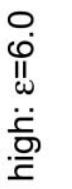

Figure 4: Contour lines showing the dependence of the evolutionarily stable strategy $\left(p_{\text {ESS }}\right)$ on the intensity of competitive dominance of slowdeveloping larvae (SDL) over fast-developing larvae (priority effect, $\alpha$ ), and changes in the fraction of caterpillars that are an individual female's offspring $(f)$. In $a$ and $b$, overall competition $\varepsilon=2.2$, a value typical for sites with low host plant (gentian) density; in $c$ and $d$, $\varepsilon=6$, a value typical for high-density sites. In $a$ and $c$, winter survival for SDL is $\mu=0.95$; in $b$ and $d$ ), it is $\mu=0.8$. Note that $p_{\text {EsS }}$ tends to increase with increasing $f$ if $\alpha$ is large but tends to decline with $f$ if $\alpha$ is small. The heavy contour lines encompass the range of $p_{\mathrm{R}}$ observed in the empirical studies. 
single female increases. This is due to the fact that delaying development of too many offspring also enhances the level of kin competition between siblings in the second season and is thus not favored by selection. The best estimates for $f(\sim 0.25)$ in low-gentian-density sites, as well as laboratory estimates for winter survival $(\mu=0.95)$, are in fact of the appropriate magnitude to stabilize the ESS in the range observed in empirical studies. However, for highdensity sites (which are much rarer than low-density sites in the field; Elmes et al. 1996), $f$ values seem to be too low to bring the predicted ESS into the range actually observed: the model predicts that an even smaller fraction of caterpillars should develop in the first year. Assuming lower values for winter mortality, which may be more realistic for natural conditions, improves the situation slightly. However, the ESS should nonetheless be highly sensitive to changes in either $\mu$ or the strength of $\alpha-$ a result in disagreement with the observed stability of the fraction of caterpillars delaying their development (Thomas et al. 1998a).

\section{Effect of Segregation}

So far we have not accounted for the effect of segregation (see the introduction to this article). Field observations indicate that a fraction $E$ as large as 0.6 of infected colonies succeed in moving their nests away from the domain of host plants (Elmes et al. 1996; Thomas et al. 1997). Evidently, the SDL carried along with such a colony will not have to compete at all with new FDL in the following season. A first, naive consideration may thus lead to the conclusion that segregation benefits the SDL only and should strengthen the selection for delayed development. However, segregation implies-if the whole population is in a steady state- that the number of ant colonies removed due to emigration into safe areas must be replaced by a similar number of uninfected colonies (Thomas et al. 1997). These colonies will provide opportunities for FDL to develop free of competition from SDL from the previous year (see fig. $1)$. This is especially true if $\alpha$ is strong, because the SDL would not profit much from segregation if they dominate the FDL anyway.

Thus, with segregation, FDL and SDL compete in only a fraction $1-E$ of colonies, while they develop independently of competition with the other cohort in a fraction $E$ of colonies (eqq. [A17], [A18], [A30]). The effect of segregation on the ESS is presented in figure 5. It is obvious that increased segregation tends to stabilize the ESS at values closer to 0.5 and diminishes sensitivity to changes in $\alpha$. This result makes sense, because both cohorts benefit from segregation, and the optimal strategy in the case of complete segregation would clearly be 0.5 (if $\mu=1$ ) no matter what the priority effect. The latter, in fact, becomes irrelevant with complete segregation because the FDL and SDL from different seasons would never compete. The important message from figure 5 is that-given the empirical evidence for segregation - the priority effect would have to be stronger than currently plausible to obtain an ESS in the range actually observed.

\section{Conclusions}

The model presented here accounts for a number of factors that are all likely to affect the evolution of delayed development in Maculinea rebeli. It demonstrates that combinations of parameter values for the priority effect $(\alpha)$, the fraction of competing siblings $(f)$, winter survival $(\mu)$, and segregation $(E)$ can account for any observable fraction of SDL in the range between 0 and 1. Interestingly, changes in overall competition $\varepsilon$ are of minor influence when $\varepsilon>2$, which is the minimum value estimated for any field site; however, a minimum competition $\varepsilon>1$ is required for the evolution of delayed development. This result is in itself important because we need not assume that time or energy constraints are responsible for delayed larval development. However, the main problem is that realistic combinations of parameters do not fix the ESS in the region of $p_{\mathrm{R}} \approx 0.25$, the observed value. General competition and kin competition alone cannot drive $p_{\mathrm{R}}$ below 0.5 (cf. Kobayashi and Yamamura 2000). In the presence of sibling competition, natural selection will favor strategies that increase the overall success of sibling larvae and not just the success of an individual caterpillar. This tends to be maximized when $p_{\mathrm{R}}$ is close to 0.5 , even if the winter mortality of SDL is very low. A similar conclusion holds for the effect of segregation, which strongly selects for delayed development but never for $p_{\text {ESS }}<0.5$ (see figs. 4, 5 for $\alpha=0$ ). Thus, among all the parameters included in our model, the priority effect is the only mechanism that theoretically allows for the evolution of $p_{\mathrm{ESS}}$ values lower than 0.5 .

Unfortunately, empirical information on parameter values in M. rebeli is incomplete. Estimates of $\varepsilon, \mu$, and $E$ are fairly reliable, but that for $f$ was only crudely and indirectly derived. Current field estimates indicate a high probability of segregation ( $E$ of nearly 0.6 ). Natural values might be lower, especially on sites with lower gentian densities, but $E$ is probably always $>0.25$. At these levels, only a very large priority effect (high $\alpha$ ) could bring predicted values for the ESS into the range observed by Thomas et al. (1998a), that is, a ratio of $3: 1$ in favor of SDL (fig. $5 b, 5 c, 5 e, 5 f)$. There are no field estimates of $\alpha$, but the data obtained from one laboratory experiment suggest that the priority effect is quite small. However, it is not unreasonable to assume that under (severe) field conditions, resident half-grown SDL might have considerable com- 

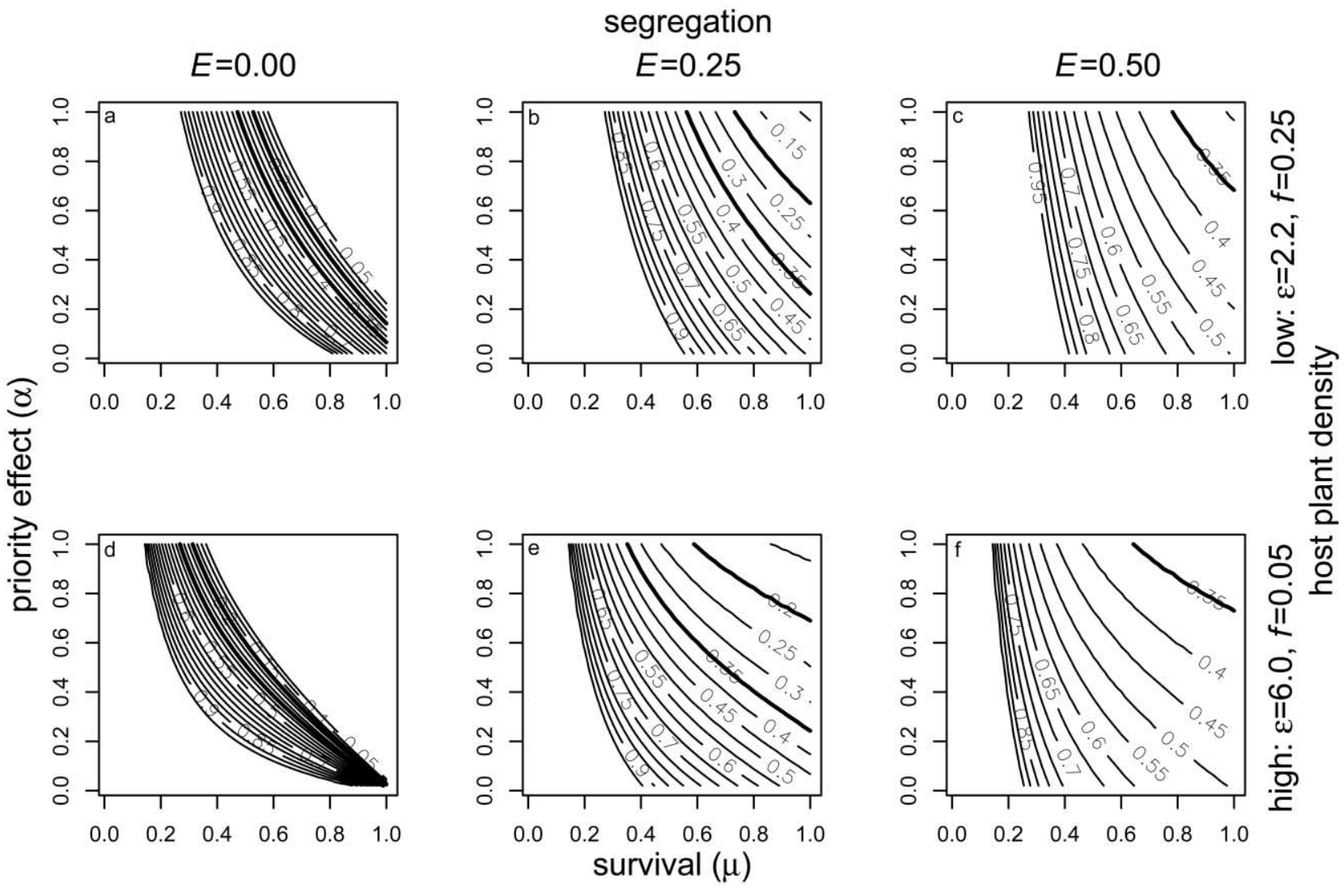

Figure 5: Effect of a segregation effect $(E)$ on the evolutionarily stable strategy under a parameter combination typical for small sites $(\varepsilon=2.2$, $f=0.25 ; a-c)$ and a combination more characteristic for large sites $(\varepsilon=6, f=0.05 ; d-f)$. Left, segregation $E=0.0 ;$ middle, $E=0.25$; right, $E=0.5$. The heavy contour lines encompass the range of $p_{\mathrm{R}}$ observed in the empirical studies.

petitive advantages over newly adopted FDL. An attempt to estimate this parameter in wild populations of $M$. rebeli is therefore key to future research on this system, but in the light of the current empirical evidence, we concede that the fit between our model's prediction and empirical observation is unsatisfactory.

Although the model incorporates four different mechanisms (overall competition, kin competition, the priority effect, and segregation) that can singly or jointly select for delayed development, additional factors could be involved. For example, environmental variability in the form of catastrophes affecting the egg or adult population could affect the evolution of developmental strategies. Strong environmental variability favors the "dilution" of reproductive investment in space and/or time. Bet hedging has been the primary argument to explain the evolution of dormancy in seeds (Cohen 1966; Ellner and Shmida 1981; Ellner 1985), crustaceans (Maffei et al. 2005), and insects (Menu and Desouhant 2002; Soula and Menu 2003). Dormancy is analogous in some ways to dispersal in space
(Hanski 1988; Hopper 1999) and has recently been suggested as a factor that might drive the evolution of delayed development in Maculinea nausithous and Maculinea teleius (Witek et al. 2006). In the case of M. rebeli, risk spreading may be an added benefit of delaying, but we believe that it cannot explain why nearly $75 \%$ of caterpillars delay growth for one season. First, M. rebeli populations are remarkably stable (Elmes et al. 1996; Thomas et al. 1998b; Nowicki et al. 2005) compared to those of other butterfly species. This could be an effect of bet hedging itself (Ellner 1985), but more likely is the consequence of the great stability of the host ant populations that usually are the limiting resource for the growth of Maculinea populations (Thomas et al. 1998b). More important, the large fraction of caterpillars delaying is not compatible with the observation that there are no $\geq 3$-year developers (Thomas et al. 1998a), despite laboratory rearing of many hundreds of caterpillars, including many SDL collected from the wild in their second year of growth. Under a bet-hedging hypothesis, a large fraction of SDL would indicate a high 
probability of environmental catastrophes (there is no empirical evidence of this) and/or very low costs of delaying (Bouteiller 1998). Yet one would then expect a substantial proportion of caterpillars to delay development for even longer time spans (Ellner 1985; Philippi 1993; Maffei et al. 2005). If, on the other hand, caterpillars for some reason cannot delay development for more than one winter, it would not make sense to bet more than $50 \%$ of the offspring on the second year if that cannot be predicted to be better than the next season. The only exception could be the presence of a biennial cycle in environmental conditions, because the majority of caterpillars would be deposited in good years (by definition) and should delay for one season to emerge in a good year again, but there is no evidence of such cycles in habitat conditions or population size in the Maculinea populations studied (and such predictable cycles would not be in agreement with the concept of bet hedging anymore).

However, there is mounting evidence (Schönrogge et al. 2000) that SDL are also present in other lowland populations of M. rebeli and in the closely related Maculinea alcon but that they occur at ratios nearer $1: 1$. This may also be the case in other Maculinea species (Witek et al. 2006). It would thus be desirable to additionally account for the benefits of bet hedging in an extended model. Unfortunately, under variable environmental conditions,

segregation

$E=0.25$
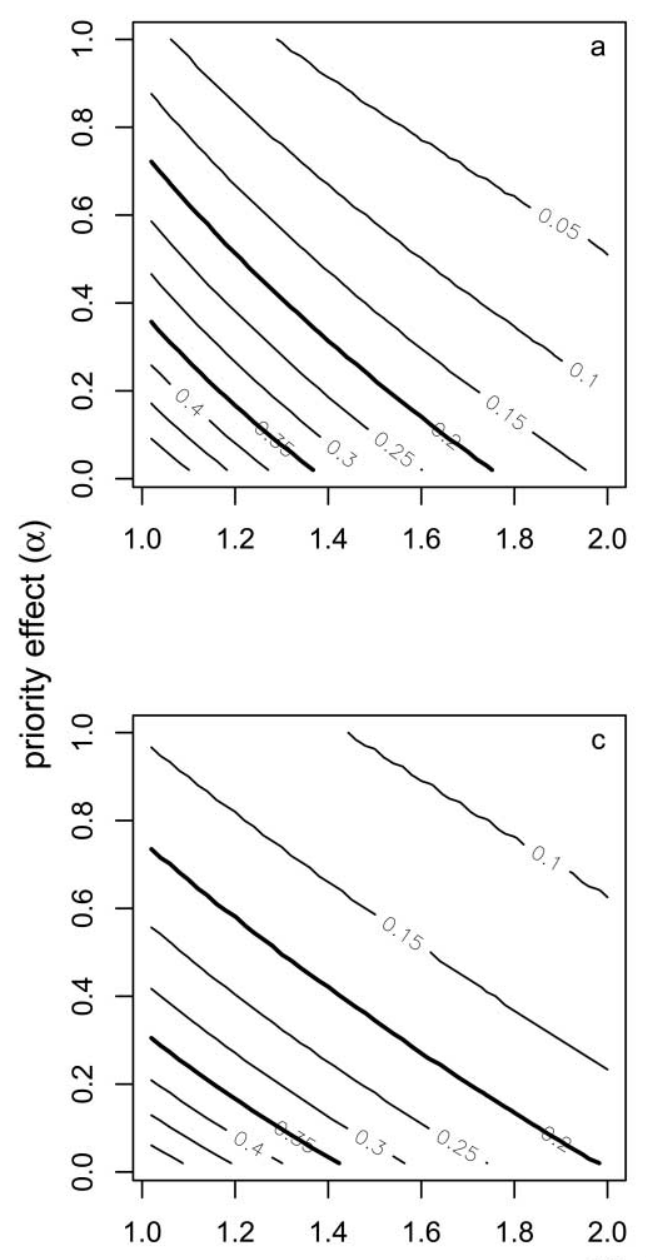

$E=0.50$

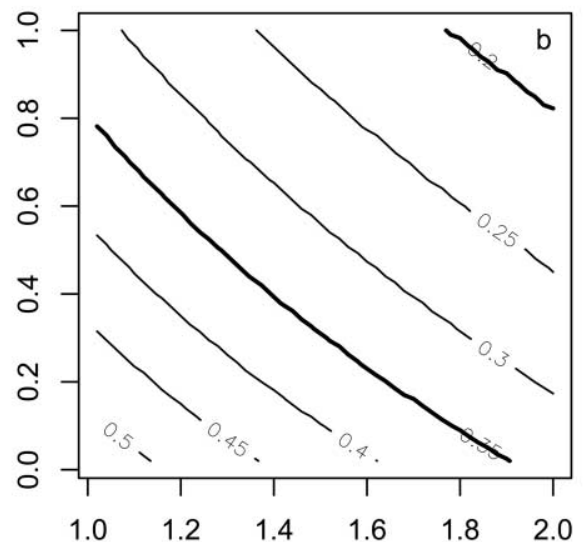

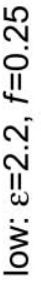

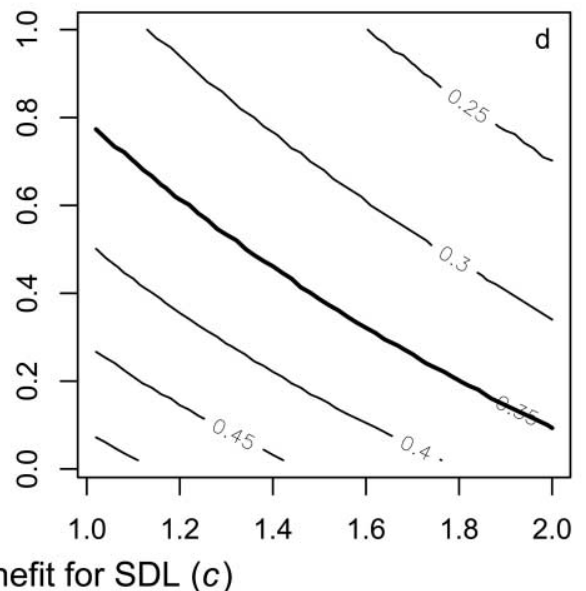

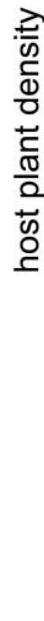

Figure 6: Exchangeability of the effect of the priority effect $(\alpha)$ with some added benefit (c) for slow-developing larvae (SDL) emerging after eclosion. Winter survival for SDL $(\mu)$ is 0.9 in all plots. Top, low-density sites; bottom, high-density sites. Values for two levels of segregation are given. The heavy contour lines encompass the range of $p_{\mathrm{R}}$ observed in empirical studies. 
lifetime reproductive success is not an appropriate measure of fitness (e.g., Heino et al. 1997; van Dooren and Metz 1998). Finding an ESS in such an extended version of the model will presumably be possible only by performing simulation experiments.

This leaves the possibility that SDL gain additional benefits from delayed growth besides the priority effect. We suggest three nonexclusive candidates. (1) In the first weeks after adoption, many fast-developing caterpillars are infested by a specialized parasitoid, Ichneumon eumerus (Wesmael), which enters Myrmica schencki nests to oviposit in only those caterpillars that are above a certain size, killing up to $50 \%$ of $M$. rebeli larvae (infected individuals die 10 months later, when their pupae produce wasps). We have weak anecdotal evidence that, despite their large size, SDL evade parasitism in their second year (Thomas and Elmes 1993; Thomas et al. 2002, 2005) and thus carry a smaller risk than FDL. (2) About 98\% of the ultimate biomass of each larva is acquired through feeding in the ant nest. After emergence, adults from SDL are somewhat heavier, and hence presumably more fecund, than those from FDL (Thomas and Elmes 1998). We have not measured the potential benefits of such a size advantage for Maculinea, but it is widely accepted that larger individuals within insect populations are fitter. This is mainly because large adults tend to live longer (both sexes), large females lay more eggs-for example, in the moths Orgyia (Tammaru et al. 2002) —and the eggs that they lay are more fertile, while large males may be more successful at attracting mates (e.g., Wigglesworth 1972; Peters and Barbosa 1977). For example, a 7\% increase in body weight (as observed in SDL $M$. rebeli, compared to FDL) corresponds to a $27 \%$ average increase in eggs laid by the bug Podiscus rostralis (Zanuncio et al. 2002) and a $12 \%$ average increase in eggs laid by the lepidopteran Streblote panda (Calvo and Molina 2005). (3) Adults from SDL emerge earlier in the season than those from FDL (fig. 1). Eventually, this provides certain benefits, for example, with respect to mating opportunities or quality of egg deposition sites. These combined differences may give SDL an advantage in survival, mating opportunities, or the number of eggs they can produce, suggesting a tradeoff between growth strategy and reproductive capability (cf. Abrams et al. 1996).

Accounting for such benefits in our model does not introduce any complications, because we simply need to multiply the fitness contribution from SDL by some constant $c>1$. Obviously, with an appropriate value of $c$, the fitness landscapes presented in the figures could be shifted into a range that better corresponds to empirical observation. Testing whether such benefits do exist is a priority for future studies. In figure 6, we show which combinations of priority effect and the aforementioned added ben- efits would lead to the evolution of $p_{\mathrm{ESS}}$ in the empirically observed range.

We conclude that quite unlikely combinations of parameters are required to lead to the evolution of the observed ratio of SDL to FDL. This has led us to consider other mechanisms that might also be involved and has helped to prioritize future research efforts on the M. alcon/ $M$. rebeli system. Furthermore, while our model has been designed for a specific situation occurring in that hostparasite system, it is structurally quite general and presumably applies to other systems of social parasitism. We can expect to find delayed development (dispersal in time) to evolve whenever close relatives compete over limited resources within a single season but not across seasons. In addition, the model may apply to situations where competition occurs in small groups on resources that are not always accessible. However, delayed development is especially likely to evolve when slowly maturing individuals gain a competitive benefit over fast developers.

\section{Acknowledgments}

This research has been financially supported by the European Union within its Research and Technical Development project EVK2-CT-2001-00126 (MacMan). We wish to thank two anonymous reviewers for their helpful and creative comments.

\section{Literature Cited}

Abrams, P. A., O. Leimar, S. Nylin, and C. Wiklund. 1996. The effect of flexible growth rates on optimal sizes and development times in a seasonal environment. American Naturalist 147:381-395.

Akino, T., J. J. Knapp, J. A. Thomas, and G. W. Elmes. 1999. Chemical mimicry and host specificity in the butterfly Maculinea rebeli, a social parasite of Myrmica ant colonies. Proceedings of the Royal Society B: Biological Sciences 266:1419-1426.

Als, T. D., D. R. Nash, and J. J. Boomsma. 2002. Geographical variation in host-ant specificity of the parasitic butterfly Maculinea alcon in Denmark. Ecological Entomology 27:403-414.

Benton, T. G., and A. Grant. 1999. Optimal reproductive effort in stochastic, density-dependent environments. Evolution 53:677688.

Blaustein, L., and J. Margalit. 1996. Priority effects in temporary pools: nature and outcome of mosquito larva-toad tadpole interactions depend on order of entrance. Journal of Animal Ecology 65:77-84.

Bouteiller, Y. 1998. Maintien d'une stratégie mixte: le polymorphisme de croissance des larves du papillon Maculinea rebeli. MS thesis. Université de Paris VI.

Brommer, J. E., L. Gustafsson, H. Pietiäinen, and J. Merilä. 2004. Single-generation estimates of individual fitness as proxies for long-term genetic contribution. American Naturalist 163:505-517. Bulmer, M. 1994. Theoretical evolutionary ecology. Sinauer, Sunderland, MA.

Calvo, D., and J. M. Molina. 2005. Fecundity-body size relationship and other reproductive aspects of Streblote panda (Lepidoptera: 
Lasiocampidae). Annals of the Entomological Society of America 98:191-196.

Cohen, D. 1966. Optimizing reproduction in a randomly varying environment. Journal of Theoretical Biology 12:119-129.

Danks, H. V. 2002. The range of insect dormancy responses. European Journal of Entomology 99:127-142.

De Vries, P. J., R. B. Cocroft, and J. Thomas. 1993. Comparison of acoustical signals in Maculinea butterfly caterpillars and their obligate host Myrmica ants. Biological Journal of the Linnean Society 49:229-238.

Edgerly, J. S., and S. P. Livdahl. 1992. Density-dependent interactions within a complex life cycle: the roles of cohort structure and mode of recruitment. Journal of Animal Ecology 61:139-150.

Eitam, A., L. Blaustein, and M. Mangel. 2005. Density and intercohort priority effects on larval Salamandra salamandra in temporary pools. Oecologia (Berlin) 146:36-42.

Ellner, S. 1985. ESS germination strategies in randomly varying environments. I. Logistic-type models. Theoretical Population Biology 28:50-79.

. 1986. Germination dimorphisms and parent-offspring conflict in seed germination. Journal of Theoretical Biology 123:173185.

Ellner, S., and A. Shmida. 1981. Why are adaptations for long-range seed dispersal rare in desert plants? Oecologia (Berlin) 51:133144.

Elmes, G. W., J. A. Thomas, and J. C. Wardlaw. 1991a. Larvae of Maculinea rebeli, a large blue butterfly and their Myrmica host ants: patterns of caterpillar growth and survival. Journal of Zoology 224:79-92.

Elmes, G. W., J. C. Wardlaw, and J. A. Thomas. 1991b. Larvae of Maculinea rebeli, a large blue butterfly, and their Myrmica host ants: wild adoption and behavior in ant nests. Journal of Zoology 223:447-460.

Elmes, G. W., R. T. Clarke, J. A. Thomas, and M. E. Hochberg. 1996. Empirical tests of specific predictions made from a spatial model of the population dynamics of Maculinea rebeli, a parasitic butterfly of red ant colonies. Acta Oecologica 17:61-80.

Elmes, G. W., J. C. Wardlaw, K. Schönrogge, J. A. Thomas, and R. T. Clarke. 2004. Food stress causes differential survival of socially parasitic caterpillars of Maculinea rebeli integrated in colonies of host and non-host Myrmica ant species. Entomologia Experimentalis et Applicata 110:53-63.

Geritz, S. A. H., E. Kisdi, G. Meszéna, and J. A. J. Metz. 1998. Evolutionarily singular strategies and the adaptive growth and branching of the evolutionary tree. Evolutionary Ecology 12:3557.

Hanski, I. 1988. Four kinds of extra long diapause in insects: a review of theory and observations. Annales Zoologici Fennici 25:37-53.

Heino, M., J. A. J. Metz, and V. Kaitala. 1997. Evolution of mixed maturation strategies in semelparous life histories: the crucial role of dimensionality of feedback environment. Philosophical Transactions of the Royal Society B: Biological Sciences 352:1647-1655.

Hochberg, M. E., J. A. Thomas, and G. W. Elmes. 1992. A modelling study of the population dynamics of a large blue butterfly, $M a-$ culinea rebeli, a parasite of red ant nests. Journal of Animal Ecology 61:397-409.

Hochberg, M. E., R. T. Clarke, G. W. Elmes, and J. A. Thomas. 1994. Population dynamic consequences of direct and indirect interactions involving a large blue butterfly and its plant and red ant hosts. Journal of Animal Ecology 63:375-391.
Hölldobler, B., and E. O. Wilson. 1990. The ants. Springer, Berlin. Hopper, K. R. 1999. Risk-spreading and bet-hedging in insect population biology. Annual Review of Entomology 44:535-560.

Kobayashi, Y., and N. Yamamura. 2000. Evolution of seed dormancy due to sib competition: effect of dispersal and inbreeding. Journal of Theoretical Biology 202:11-24.

Maffei, C., D. Vagaggini, P. Zarattini, and G. Mura. 2005. The dormancy problem for Crustacea anostraca: a rigorous model connecting hatching strategies and environmental conditions. Ecological Modelling 185:469-481.

Maynard Smith, J., and G. R. Price. 1973. The logic of animal conflict. Nature 246:15-18.

Menu, F., and D. Debouzie. 1993. Coin-flipping plasticity and prolonged diapause in insects: example of the chestnut weevil Curculio elephas (Coleoptera, Curculionidae). Oecologia (Berlin) 93:367373.

Menu, F., and E. Desouhant. 2002. Bet-hedging for variability in life cycle duration: bigger and later-emerging chestnut weevils have increased probability of a prolonged diapause. Oecologia (Berlin) 132:167-174.

Menu, F., J.-P. Roebuck, and M. Viala. 2000. Bet-hedging diapause strategies in stochastic environments. American Naturalist 155: 724-734.

Metz, J. A. J., S. D. Mylius, and O. Diekmann. 1996. When does evolution optimise? on the relation between types of density dependence and evolutionarily stable life history parameters. Pages 1-24 in IIASA Working Paper WP-96-004. International Institute for Applied Systems Analysis, Laxenburg.

Mylius, S. D., and O. Diekmann. 1995. On evolutionarily stable life histories, optimization and the need to be specific about density dependence. Oikos 74:218-224.

Nowicki, P., J. Settele, J. A. Thomas, and M. Woyciechowski. 2005. A review of population structure of Maculinea butterflies. Pages 144-149 in J. Settele, E. Kühn, and J. A. Thomas, eds. Studies on the ecology and conservation of butterflies in Europe. Vol. 2. Species ecology along a European gradient: Maculinea butterflies as a model. Pensoft, Sofia.

Peck, G. W., and W. E. Walton. 2005. Effect of different assemblages of larval foods on Culex quinquefasciatus and Culex tarsalis (Diptera: Culicidae) growth and whole body stoichiometry. Environmental Entomology 34:767-774.

Peters, T. M., and P. Barbosa. 1977. Influence of population density on size, fecundity, and developmental rate of insects in culture. Annual Review of Entomology 22:431-450.

Philippi, T. 1993. Bet-hedging germination of desert annuals: beyond the first year. American Naturalist 142:474-487.

Schönrogge, K., J. C. Wardlaw, J. A. Thomas, and G. W. Elmes. 2000. Polymorphic growth rates in myrmecophilous insects. Proceedings of the Royal Society B: Biological Sciences 267:771-777.

Schönrogge, K., J. C. Wardlaw, A. J. Peters, S. Everett, J. A. Thomas, and G. W. Elmes. 2004. Changes in chemical signature and host specificity from larval retrieval to full social integration in the myrmecophilous butterfly Maculinea rebeli. Journal of Chemical Ecology 30:91-107.

Shorrocks, B., and M. Bingley. 1994. Priority effects and species coexistence: experiments with fungal-breeding Drosophila. Journal of Animal Ecology 63:799-806.

Soula, B., and F. Menu. 2003. Variability in diapause duration in the chestnut weevil: mixed ESS, genetic polymorphism or bet-hedging? Oikos 100:574-580. 
Tammaru, T., T. Esperk, and I. Castellanos. 2002. No evidence for costs of being large in females of Orgyia spp. (Lepidoptera, Lymantriidae): larger is always better. Oecologia (Berlin) 133:430438.

Thomas, J. A., and G. W. Elmes. 1993. Specialized searching and the hostile use of allomones by a parasitoid whose host, the butterfly Maculinea rebeli, inhabits ant nests. Animal Behaviour 45:593602.

- 1998. Higher productivity at the cost of increased hostspecificity when Maculinea butterfly larvae exploit ant colonies through trophallaxis rather than by predation. Ecological Entomology 23:457-464.

- 2001. Food-plant niche selection rather than the presence of ant nests explains oviposition patterns in the myrmecophilous butterfly genus Maculinea. Proceedings of the Royal Society B: Biological Sciences 268:471-477.

Thomas, J. A., and J. C. Wardlaw. 1992. The capacity of a Myrmica ant nest to support a predacious species of Maculinea butterfly. Oecologia (Berlin) 91:101-109.

Thomas, J. A., M. L. Munguira, J. Martin, and G. W. Elmes. 1991. Basal hatching by Maculinea butterfly eggs: a consequence of advanced myrmecophily. Biological Journal of the Linnean Society 44:175-184.

Thomas, J. A., G. W. Elmes, and J. C. Wardlaw. 1993. Contest competition among Maculinea rebeli butterfly larvae in ant nests. Ecological Entomology 18:73-76.

Thomas, J. A., G. W. Elmes, R. T. Clarke, K. G. Kim, M. L. Munguira, and M. E. Hochberg. 1997. Field evidence and model predictions of butterfly-mediated apparent competition between gentian plants and red ants. Acta Oecologica 18:671-684.

Thomas, J. A., R. T. Clarke, G. W. Elmes, and M. E. Hochberg. 1998a. Polymorphic growth in larvae of the butterfly Maculinea rebeli, a social parasite of Myrmica ant colonies. Proceedings of the Royal Society B: Biological Sciences 265:1895-1901.
Thomas, J. A., G. W. Elmes, and J. C. Wardlaw. 1998b. Population dynamics in the genus Maculinea (Lepidoptera: Lycaenidae). Pages 261-290 in J. P. Dempster and I. F. G. McLean, eds. Insect populations in theory and in practice. Kluwer, Dordrecht.

Thomas, J. A., J. J. Knapp, T. Akino, S. Gerty, S. Wakamura, D. J. Simcox, J. C. Wardlaw, and G. W. Elmes. 2002. Parasitoid secretions provoke ant warfare: subterfuge used by a rare wasp may be the key to an alternative type of pest control. Nature 417:505-506.

Thomas, J. A., K. Schönrogge, and G. W. Elmes. 2005. Specialisations and host associations of social parasites of ants. Pages 479-518 in M. D. E. Fellowes, G. J. Holloway, and J. Rolff, eds. Insect evolutionary ecology. CABI, Wallingford.

van Dooren, T. J. M., and J. A. J. Metz. 1998. Delayed maturation in temporally structured populations with non-equilibrium dynamics. Journal of Evolutionary Biology 11:41-62.

Venable, D. L., and J. S. Brown. 1993. The population-dynamic functions of seed dispersal. Vegetatio 108:31-55.

Wigglesworth, V. B. 1972. Principles of insect physiology. Chapman \& Hall, London.

Witek, M., E. B. Sliwinska, P. Skórka, P. Nowicki, J. Settele, and M. Woyciechowski. 2006. Polymorphic growth in larvae of Maculinea butterflies, as an example of biennialism in myrmecophilus insects. Oecologia (Berlin) 148:729-733.

Wolfram Research. 1999. Mathematica. Version 4.0. Wolfram Research, Champaign, IL.

Zanuncio, J. C., A. J. Molina-Rugama, G. P. Santos, and F. d. S. Ramalho. 2002. Effect of body weight on fecundity and longevity of the stinkbug predator Podisus rostralis. Pesquisa Agropecuaria Brasileira 37:1225-1230.
Associate Editor: Peter D. Taylor Editor: Michael C. Whitlock 